\title{
Aerodynamic Phenomena Caused by the Passage of a Train. Part 2: Pressure Influence on Passing Trains
}

\begin{abstract}
Andrzej ZBIEĆ ${ }^{1}$
\section{Summary}

In the series of articles describing the aerodynamic phenomena caused by the passage of a train, the effects of a train running at high speed on itself, on other trains, on objects on the track and on people are characterized. This impact can be of two types - generated pressure and slipstream. Apart from the literature analysis, the author's research is also taken into account. The second part presents the effect of pressure changes on the front and side surfaces of passing trains. Conclusions concerning side windows and windscreens in high-speed railway vehicles and older type railway vehicles with lower allowable speeds and the possibility of using various rolling stock on the same lines are presented.
\end{abstract}

Keywords: rolling stock, high-speed railways, aerodynamic phenomena

\section{Introduction}

The first part of the cycle described a general classification of aerodynamic phenomena divided into pressure changes and slipstream by the type of effects. It also presented changes of pressure in the open air, caused by a train passage, and the influence of pressure on various objects located on the track. Primary normative documents concerning aerodynamic issues were specified as well. It also depicted conclusions on the construction of a high-speed railway vehicle as well as durability and location of the structure at high-speed lines. The second part of the cycle continues matters regarding pressure changes, yet this time focuses on those arising from the mutual impact of moving trains on their front and side surfaces.

\section{Effects of pressure on train side surfaces}

Similar to influencing objects located near the track, a passing train also has an effect on an immobile train or running train on a neighboring track. Since the side aerodynamic force (perpendicular to the surface of the train) grows proportionally to the square of the speed, it is necessary to analyze whether values of forces (pressures) do or do not pose a threat to the structure of the vehicles being passed.
As one work proved [5], it is the train running at a higher speed that influences a slower train and other objects, and not the other way round. Similar conclusions were evoked in the report [1], taking into account the publications of other authors $[2,4,9]$ :

1. "The amplitude of the pressure wave induced by the passing train onto the observing train during passing is dependent only on the speed of the passing train, its nose shape, and the spacing between the two trains, but not on the speed of the observing train";

2. "While the amplitude of the pressure pulse generated by the passing train is theoretically unaffected by the motion of the observing train, measurements conducted by the French and Germans showed that there is a 30 to 40 percent increase in differential pressure coefficients when both the observing and passing trains are moving at the same speed";

3. "Experimental measurements have been made to measure the aerodynamic pressures generated between two passing trains. When a moving train passes a stationary train, the aerodynamic pressures exerted on the stationary train are more severe than those on a moving train".

Figure 1 shows results of the 2D simulations for four variants of train movement:

- the train equipped with pressure sensors (test model) runs in the open air,

\footnotetext{
${ }^{1}$ M.Sc.Eng.; Railway Research Institute, Rolling Stock Testing Laboratory; e-mail: azbiec@ikolej.pl.
} 
- both trains run at the same speed in opposite directions,

- the train equipped with pressure sensors (test model) goes past the stopped train,

- the running train goes past the stopped test train, equipped with pressure sensors.

The dimensionless pressure coefficient $\Delta \mathrm{Cp}$ (Pressure Coefficient) in point P-1 of the bodywork has been presented as the function of distance between trains referring to the width of trains - dimensionless size $\mathrm{X}$.

The calculations presented clearly demonstrate that the highest pressure is recorded when the moving train passes the other stopped train; at this moment the side wall of the immobile train is affected by considerable pressure changes. The second largest change in pressure occurs when both trains go past each other at the same speed. For this reason, there is no hazard related
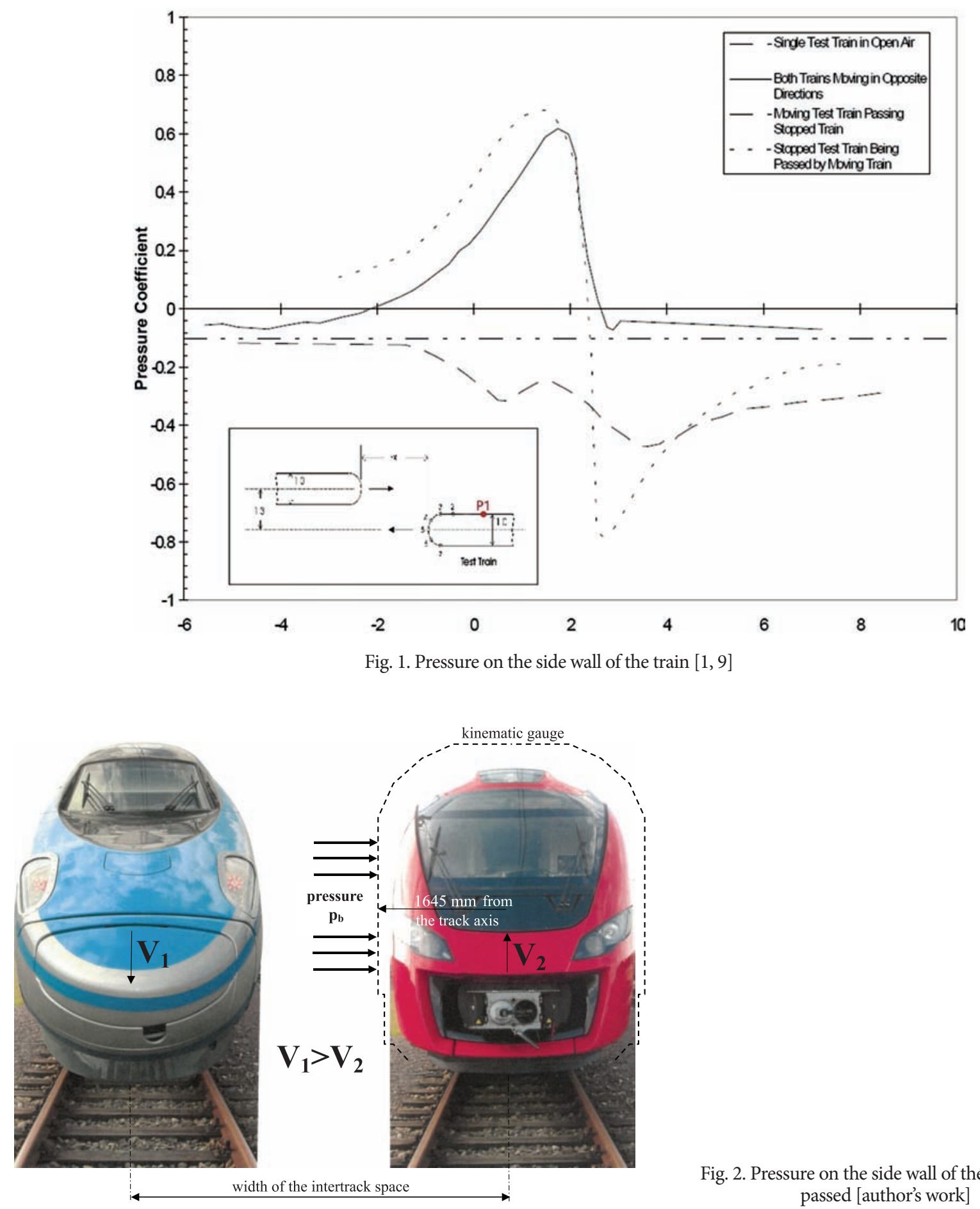

Fig. 2. Pressure on the side wall of the train being passed [author's work] 
to effects of the pressure induced by the slower train on the train moving at a higher speed. When results of measurements or simulations are unavailable, to calculate the effects of passing trains, it is possible to make use of the formulas applicable to the impact of pressure on vertical structures (Section 2.2 in Part 1).

To calculate the values of pressure $p_{\mathrm{b}}$ on the side wall of the train being passed, the most unfavorable assumption has been adopted. According to the aforesaid assumption, this train is as close to the fast train as possible - as shown in Figure 2, its side wall contacts the kinematic gauge - the size $1645 \mathrm{~mm}$ from the track axis as per the PN-EN 15273-2 standard [8]. In reality, the distance between trains will be slightly bigger and pressures slightly smaller than those calculated below because the average widths of Polish passenger cars range from $2.68 \mathrm{~m}$ to $2.88 \mathrm{~m}$.

Pursuant to TSI INF [3], the following minimum widths of the intertrack space are adopted (distances between axes of neighboring tracks which both trains move on):

- $3.8 \mathrm{~m}$ for the speed of $160 \mathrm{~km} / \mathrm{h}<V \leq 200 \mathrm{~km} / \mathrm{h}$;

- $4.0 \mathrm{~m}$ for the speed of $200 \mathrm{~km} / \mathrm{h}<V \leq 250 \mathrm{~km} / \mathrm{h}$;

- $4.2 \mathrm{~m}$ for the speed of $250 \mathrm{~km} / \mathrm{h}<V \leq 300 \mathrm{~km} / \mathrm{h}$;

- $4.5 \mathrm{~m}$ for the speed of $V>300 \mathrm{~km} / \mathrm{h}$.

Table 1 and Figure 3 depict pressures on the side wall of the conventional train being passed, depending on the speed of the high-speed train and width of the intertrack space.

Following Table 1, the maximum value of pressure influencing the moving or immobile train on the neighboring track is below $1000 \mathrm{~Pa}$. Such a value of pressure is not dangerous to the sheathing of passenger cars and freight cars and other fixed elements. The only element of the passenger car that could be damaged as a result of impact of a fast-changing wave of pressure is the window. However, pursuant to the UIC 566 Leaflet [10] p. 4.2.2.2, windows are subject to the following endurance fatigue tests:

- $\pm 2500 \mathrm{~Pa}$ - loading pressure;

- $10^{6}$ - number of loading cycles;

- $3 \mathrm{~Hz}$ - frequency of loading.

Table 1

Pressures on the side wall of the train being passed

\begin{tabular}{|c|c|c|c|c|}
\hline \multirow{2}{*}{$\begin{array}{c}\text { Speed } V_{1} \\
{[\mathbf{k m} / \mathbf{h}]}\end{array}$} & \multicolumn{4}{|c|}{ Pressure $\boldsymbol{p}_{\boldsymbol{b}}[\mathrm{Pa}]$} \\
\cline { 2 - 5 } & $\mathbf{3 , 8}[\mathbf{m}]$ & $\mathbf{4 , 0}[\mathbf{m}]$ & $\mathbf{4 , 2}[\mathbf{m}]$ & $\mathbf{4 , 5}[\mathbf{m}]$ \\
\hline $\mathbf{1 6 0}$ & 328,3 & 282,0 & 245,2 & 202,8 \\
\hline $\mathbf{1 8 0}$ & 415,5 & 356,8 & 310,3 & 256,6 \\
\hline $\mathbf{2 0 0}$ & 512,9 & 440,6 & 383,1 & 316,8 \\
\hline $\mathbf{2 2 0}$ & - & 533,1 & 463,5 & 383,3 \\
\hline $\mathbf{2 4 0}$ & - & 634,4 & 551,6 & 456,2 \\
\hline $\mathbf{2 5 0}$ & - & $\mathbf{6 8 8 , 4}$ & $\mathbf{5 9 8 , 6}$ & $\mathbf{4 9 5 , 0}$ \\
\hline $\mathbf{2 6 0}$ & - & - & 647,4 & 535,4 \\
\hline $\mathbf{2 8 0}$ & - & - & 750,8 & 620,9 \\
\hline $\mathbf{3 0 0}$ & - & - & 861,9 & 712,8 \\
\hline $\mathbf{3 2 0}$ & - & - & - & 811,0 \\
\hline $\mathbf{3 4 0}$ & - & - & - & 915,6 \\
\hline $\mathbf{3 5 0}$ & - & - & - & 970,2 \\
\hline
\end{tabular}

[Author's work].

Based on the window testing parameters, even the strongest load of pressure from the train that moves on the neighboring track at a speed of $350 \mathrm{~km} / \mathrm{h}$, assuming the intertrack space is $4.5 \mathrm{~m}$, is over 2.5 times lower than the pressure during the fatigue test. As for intertrack spaces with lower width, the allowable
Fig. 3. Pressures on the side wall of the train being passed [author's work]

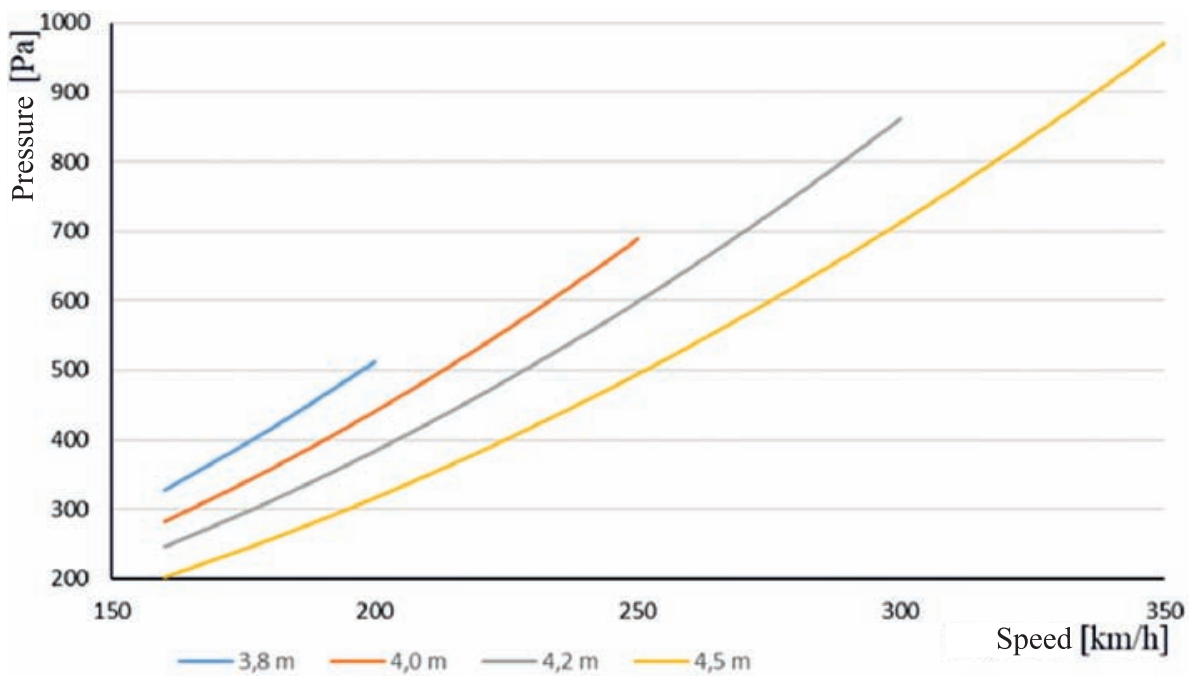


speeds are lower, as are the corresponding maximum pressures (2.9 times, 3.6 times and 4.9 times, respectively). We can therefore conclude that all passenger cars and multiple units whose windows have been tested for compliance with the UIC 566 Leaflet [10] can freely run on the same routes as high-speed trains. There is no need to replace windows in these cars, increase the intertrack space width or undertake any other corrective measures. The only peril is the entire glass being "sucked out" in the event it has been improperly mounted in the vehicle sheathing. The force that influences the window is directly proportional to its surface. Thus, with the same pressure: the larger the surface of the window, the stronger the forces influencing the window and in effect the stronger it must be fixed.

\section{Effect of pressure on train front surfaces}

The issue of pressure effects on the train front surfaces has been limited to the impact of pressure on windscreens. Similar to the effects on side surfaces, it has been assumed that the vehicle sheathing is sufficiently durable and the only element that could be damaged due to a fast-changing pressure wave is the windscreen of traction vehicles. The effects of pressure on windscreens is different than the effects of pressure on side windows. Additionally, conversely to effects on train side surfaces, it is the windscreen of the faster train that is more exposed to impact of the larger pressure, and the effect of the pressure coming from the train that moves on the neighboring track will be lower. However, it is necessary to check the gravity of this pressure, affecting the windscreens of locomotives which carry conventional trains and older types of electric multiple units as well as on trains intended for high-speed routes, although they should already be equipped with sufficiently durable windows. The PN-EN 14067-4 standard [6] does not specify any formulas to calculate the pressure on the vehicle face. Calculations were performed with the use of the formula taken from the work [5]:

$$
p_{s}=0.5 \cdot \delta_{1} \cdot \rho \cdot V_{p}^{2}+0.5 \cdot \delta \cdot \rho \cdot V_{p m}^{2},
$$

where:

$\rho=1.225 \mathrm{~kg} / \mathrm{m}^{3}$ - air density (as in Section 2.2 in Part 1);

$V_{p}$ - speed of the train for which the window-affecting pressure is calculated;

$V_{p m}$ - speed of the train being passed;

$\delta_{1}-$ pressure coefficient on the locomotive front surface, for flat windscreens $\delta_{1}=1$, as per [5], p. 64;

$\delta$ - pressure growth coefficient on the locomotive face, for track spacing $4 \mathrm{~m} \delta=0.6 \div 0.8$, as per [5], p. 64 .
For the purposes of calculations, the average value of the pressure growth coefficient on the locomotive face has been adopted (impact from the train being passed) as $\delta=0.7$. Since no coefficients for other intertrack space widths have been specified, for the intertrack space whose width is $3.8 \mathrm{~m}$ and $4.2 \mathrm{~m}$ - due to inconsiderable differences of width (only $\pm 20 \mathrm{~cm}$ ) - the same value of the coefficient has been adopted. The exception is the intertrack space of $4.5 \mathrm{~m}$ (wider by $50 \mathrm{~cm}$ ), where the value of $\delta(4.5 \mathrm{~m})=0.6$ (the wider the intertrack space, the lower the impact of pressure growth from the train which moves on the neighboring track) was chosen. The pressure coefficient on the locomotive front surface is the same as in the case of flat screens, $\delta_{1}=1$ (the most unfavorable case). The more aerodynamic the shape of the window and the entire face of the train, the lower this coefficient, for example, for a sphere, it is $0.2 \div 0.4$.

Table 2 and Figure 4 present pressures on the highspeed train windscreen, depending on the speed of passing trains. In turn, Table 3 and Figure 5 show pressures on the windscreen of the train being passed, depending on the speeds of both trains. According to the minimum values of the intertrack space width, stipulated in Section 2, as per TSI INF [3], it has been assumed that up to the speed of $300 \mathrm{~km} / \mathrm{h}$, passage takes place on tracks with the intertrack space width of $3.8 \div 4.2 \mathrm{~m}(\delta=0.7)$, and above this speed - on tracks with the intertrack space width of $4.5 \mathrm{~m}(\delta=0.6)$. This is why the value of pressure in Table 3 is lower with the increase in highspeed train speed from $V_{1}=300 \mathrm{~km} / \mathrm{h}$ to $V_{1}=320 \mathrm{~km} / \mathrm{h}$ and hence the discontinuity of curves in Figure 5.

Table 4 presents an increase in pressure (in \%) on the high-speed train windscreen, depending on the speed of the train being passed, with reference to the pressure at its maximum speed $V_{1}=350 \mathrm{~km} / \mathrm{h}$ and $V_{2}=0$ (the train being passed is immobile).

Table 5 depicts an increase in pressure (in \%) on the windscreen of the train being passed for various speeds of the high-speed train $V_{1}$, in relation to the pressure at various maximum speeds of the train being passed $\left(V_{2 \max }=120 / 140 / 160 / 180 / 200 \mathrm{~km} / \mathrm{h}\right)$ and the stopped high-speed train $\left(V_{1}=0 \mathrm{~km} / \mathrm{h}\right)$.

Tables 4 and 5 explicitly show that, with regard to a high-speed train with a maximum speed of $350 \mathrm{~km} / \mathrm{h}$, passing a slower train (at a speed of $200 \mathrm{~km} / \mathrm{h}$ ) does not cause a substantial increase in pressure on its windscreen - max. 1.2 times. The opposite applies with regard to the train being passed - when meeting the train that runs at a speed of $350 \mathrm{~km} / \mathrm{h}$, the rise in pressure on its windscreen changes considerably:

- by nearly 3 times (2.84) for the maximum speed of $200 \mathrm{~km} / \mathrm{h}$ of the train being passed,

- by nearly 4 times (3.87) for the maximum speed of $160 \mathrm{~km} / \mathrm{h}$ of the train being passed,

- up to over 6 times (6.1) for the maximum speed of $120 \mathrm{~km} / \mathrm{h}$ of the train being passed. 
Pressures on the high-speed train windscreen

\begin{tabular}{|c|c|c|c|c|c|c|}
\hline \multirow{3}{*}{$\begin{array}{c}\text { Speed } V_{1} \\
\text { (high-speed } \\
\text { train) }[\mathrm{km} / \mathrm{h}]\end{array}$} & \multicolumn{6}{|c|}{ Pressure $p_{\mathrm{s}}[\mathrm{Pa}]$} \\
\hline & \multicolumn{6}{|c|}{ Speed $V_{2}$ (train being passed) } \\
\hline & $0 \mathrm{~km} / \mathrm{h}$ & $120 \mathrm{~km} / \mathrm{h}$ & $140 \mathrm{~km} / \mathrm{h}$ & $160 \mathrm{~km} / \mathrm{h}$ & $180 \mathrm{~km} / \mathrm{h}$ & $200 \mathrm{~km} / \mathrm{h}$ \\
\hline $\mathbf{0}$ & 0 & 476 & 648 & 847 & 1072 & 1323 \\
\hline 160 & 1210 & 1686 & 1858 & 2057 & 2282 & 2533 \\
\hline 180 & 1531 & 2008 & 2180 & 2378 & 2603 & 2855 \\
\hline 200 & 1890 & 2367 & 2539 & 2737 & 2962 & 3214 \\
\hline 220 & 2287 & 2764 & 2936 & 3134 & 3359 & 3611 \\
\hline 240 & 2722 & 3199 & 3371 & 3569 & 3794 & 4046 \\
\hline 250 & 2954 & 3430 & 3602 & 3801 & 4026 & 4277 \\
\hline 260 & 3195 & 3671 & 3843 & 4042 & 4267 & 4518 \\
\hline 280 & 3705 & 4182 & 4354 & 4552 & 4777 & 5029 \\
\hline 300 & 4253 & 4730 & 4902 & 5100 & 5325 & 5577 \\
\hline 320 & 4840 & 5248 & 5395 & 5565 & 5758 & 5974 \\
\hline 340 & 5463 & 5872 & 6019 & 6189 & 6382 & 6598 \\
\hline 350 & 5789 & 6198 & 6345 & 6515 & 6708 & 6924 \\
\hline
\end{tabular}

[Author's work].

Fig. 4. Pressures on the high-speed train windscreen [author's work]

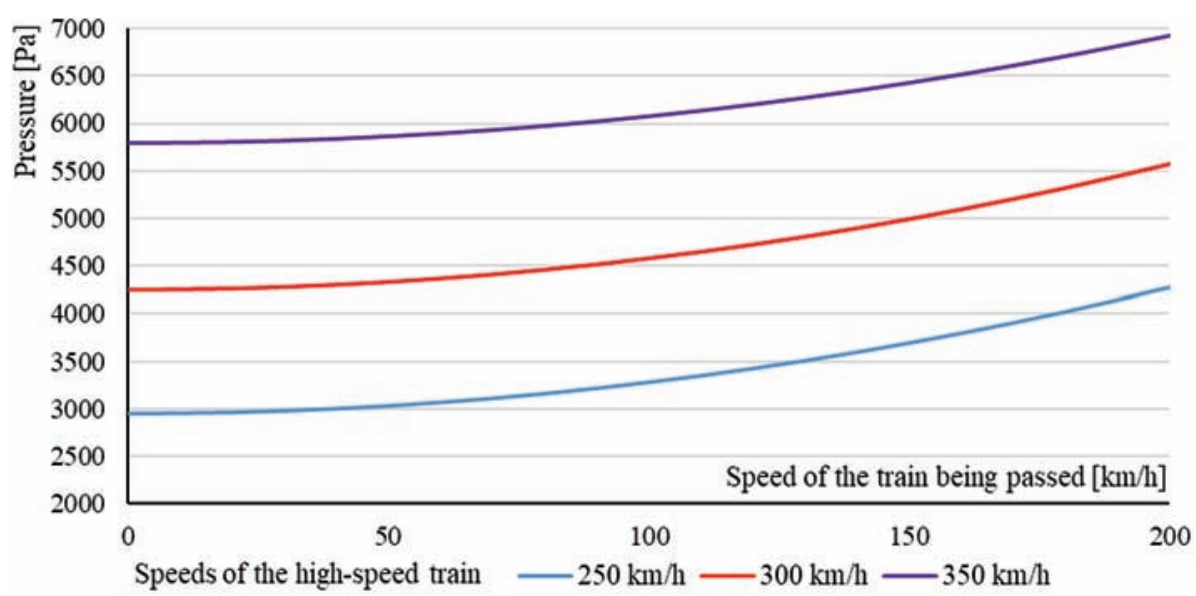

Table 3

Pressures on windscreen of the train being passed [author's work]

\begin{tabular}{|c|c|c|c|c|c|c|}
\hline \multirow{3}{*}{$\begin{array}{c}\text { Speed } V_{1} \\
\text { (high-speed } \\
\text { train) }[\mathrm{km} / \mathrm{h}]\end{array}$} & \multicolumn{6}{|c|}{ Pressure $p_{\mathrm{s}}[\mathrm{Pa}]$} \\
\hline & \multicolumn{6}{|c|}{ Speed $V_{2}$ (train being passed) } \\
\hline & $0 \mathrm{~km} / \mathrm{h}$ & $120 \mathrm{~km} / \mathrm{h}$ & $140 \mathrm{~km} / \mathrm{h}$ & $160 \mathrm{~km} / \mathrm{h}$ & $180 \mathrm{~km} / \mathrm{h}$ & $200 \mathrm{~km} / \mathrm{h}$ \\
\hline $\mathbf{0}$ & 0 & 681 & 926 & 1210 & 1531 & 1890 \\
\hline 160 & 847 & 1527 & 1773 & 2057 & 2378 & 2737 \\
\hline 180 & 1072 & 1752 & 1998 & 2282 & 2603 & 2962 \\
\hline 200 & 1323 & 2004 & 2250 & 2533 & 2855 & 3214 \\
\hline 220 & 1601 & 2282 & 2528 & 2811 & 3132 & 3492 \\
\hline 240 & 1906 & 2586 & 2832 & 3115 & 3437 & 3796 \\
\hline 250 & 2068 & 2748 & 2994 & 3278 & 3599 & 3958 \\
\hline 260 & 2236 & 2917 & 3163 & 3446 & 3768 & 4127 \\
\hline 280 & 2594 & 3274 & 3520 & 3804 & 4125 & 4484 \\
\hline 300 & 2977 & 3658 & 3904 & 4187 & 4509 & 4868 \\
\hline 320 & 2904 & 3584 & 3830 & 4114 & 4435 & 4794 \\
\hline 340 & 3278 & 3959 & 4204 & 4488 & 4809 & 5168 \\
\hline 350 & 3474 & 4154 & 4400 & 4684 & 5005 & 5364 \\
\hline
\end{tabular}

[Author's work]. 


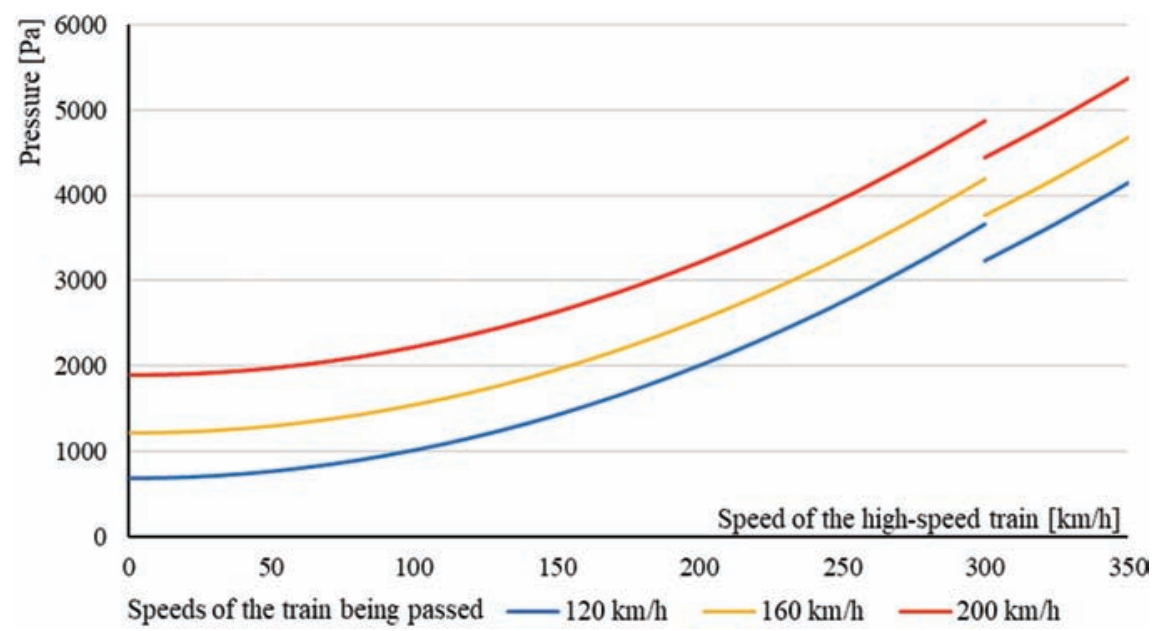

Fig. 5. Pressures on windscreen of the train being passed [author's work]

Table 4

Increase in pressure (in \%) on the high-speed train windscreen in relation to $V_{1}=350 \mathrm{~km} / \mathrm{h}$ and $V_{2}=0 \mathrm{~km} / \mathrm{h}$

\begin{tabular}{|c|c|c|c|c|c|c|}
\hline \multirow{2}{*}{$\begin{array}{c}\text { Speed } \boldsymbol{V}_{\mathbf{1}} \\
\text { (high-speed } \\
\text { train) }[\mathbf{k m} / \mathbf{h}]\end{array}$} & \multicolumn{5}{|c|}{ Pressure increase [\%] } \\
\cline { 2 - 7 } & $\mathbf{0} \mathbf{~ k m} / \mathbf{h}$ & $\mathbf{1 2 0} \mathbf{~ k m} / \mathbf{h}$ & $\mathbf{1 4 0} \mathbf{~ k m} / \mathbf{h}$ & $\mathbf{1 6 0} \mathbf{~ k m} / \mathbf{h}$ & $\mathbf{1 8 0} \mathbf{~ k m} / \mathbf{h}$ & $\mathbf{2 0 0} \mathbf{~ k m} / \mathbf{h}$ \\
\hline $\mathbf{0}$ & 0 & 8 & 11 & 15 & 19 & 23 \\
\hline $\mathbf{1 6 0}$ & 21 & 29 & 32 & 36 & 39 & 44 \\
\hline $\mathbf{1 8 0}$ & 26 & 35 & 38 & 41 & 45 & 49 \\
\hline $\mathbf{2 0 0}$ & 33 & 41 & 44 & 47 & 51 & 56 \\
\hline $\mathbf{2 2 0}$ & 40 & 48 & 51 & 54 & 58 & 62 \\
\hline $\mathbf{2 4 0}$ & 47 & 55 & 58 & 62 & 66 & 70 \\
\hline $\mathbf{2 5 0}$ & 51 & 59 & 62 & 66 & 70 & 74 \\
\hline $\mathbf{2 6 0}$ & 55 & 63 & 66 & 70 & 74 & 78 \\
\hline $\mathbf{2 8 0}$ & 64 & 72 & 75 & 79 & 83 & 87 \\
\hline $\mathbf{3 0 0}$ & 73 & 82 & 85 & 88 & 92 & 96 \\
\hline $\mathbf{3 2 0}$ & 84 & 91 & 93 & 96 & 99 & 103 \\
\hline $\mathbf{3 4 0}$ & 94 & 101 & 104 & 107 & 110 & 114 \\
\hline $\mathbf{3 5 0}$ & 100 & 107 & 110 & 113 & 116 & 120 \\
\hline
\end{tabular}

[Author's work].

Table 5

Pressure increase (in \%) on the windscreen of the train being passed in relation to pressure at its maximum speed $\left(V_{2 \max }\right)$ and $V_{1}=0 \mathrm{~km} / \mathrm{h}$

Speed $V_{1}$ (highspeed train) $[\mathrm{km} / \mathrm{h}]$
Pressure increase [\%]

Max. speed $V_{2 \text { max }}$ (train being passed)

\begin{tabular}{|c|c|c|c|c|}
\hline $120 \mathrm{~km} / \mathrm{h}$ & $140 \mathrm{~km} / \mathrm{h}$ & $160 \mathrm{~km} / \mathrm{h}$ & $180 \mathrm{~km} / \mathrm{h}$ & $200 \mathrm{~km} / \mathrm{h}$ \\
\hline 100 & 100 & 100 & 100 & 100 \\
\hline 224 & 191 & 170 & 155 & 145 \\
\hline 258 & 216 & 189 & 170 & 157 \\
\hline 294 & 243 & 209 & 186 & 170 \\
\hline 335 & 273 & 232 & 205 & 185 \\
\hline 380 & 306 & 258 & 224 & 201 \\
\hline 404 & 323 & 271 & 235 & 209 \\
\hline 429 & 341 & 285 & 246 & 218 \\
\hline 481 & 380 & 314 & 269 & 237 \\
\hline 538 & 421 & 346 & 294 & 258 \\
\hline 527 & 413 & 340 & 290 & 254 \\
\hline 582 & 454 & 371 & 314 & 273 \\
\hline 610 & 475 & 387 & 327 & 284 \\
\hline
\end{tabular}


These data prove that the use of diverse rolling stock on the same lines may entail the potential risk of damage to windscreens in trains with lower maximum speeds, particularly the older rolling stock running at maximum speeds of $120 \mathrm{~km} / \mathrm{h}$. This is very dangerous because at times when the rolling stock was designed for maximum speeds of $120 \mathrm{~km} / \mathrm{h}$ and $160 \mathrm{~km} / \mathrm{h}$, the engineers and manufacturers of those times could not anticipate that this rolling stock would run on the same lines together with trains whose top speeds reach $350 \mathrm{~km} / \mathrm{h}$.

Pressures on windscreens substantially exceed the pressure applicable to side windows (2500 Pa). Until recently, the only study conducted while testing the durability of traction vehicle windscreens was shooting a special bullet at these windows. This trial is so critical that no additional tests checking windscreen resistance to pressure were required. Before, this test was carried out in accordance with the UIC 651 Leaflet [11], and since 2007 also as per the PN-EN 15152 standard [7] (up-to-date issue of the standard comes from 2019). The method of conducting the test as per the UIC Leaflet slightly deviates from the method specified in the standard because it is also necessary to check the resistance of the window to impact with minor stones (gravel). However the primary parameter - the speed of a bullet hitting the window was and still is calculated on the basis of the following relationship:

$$
V_{\mathrm{p}}=V_{e}+160 \mathrm{~km} / \mathrm{h} \text {, }
$$

where:

$$
\begin{aligned}
& V_{p}-\text { speed of the bullet } \\
& V_{e}-\text { maximum operating speed of the vehicle in } \\
& \text { question. }
\end{aligned}
$$

Specifying the speed of the bullet arose from the maximum speed of trains $-160 \mathrm{~km} / \mathrm{h}$. It was assumed that some hard item may be thrown out of the train running at such a speed and then hit the windscreen of the train that comes from the opposite side. So far this test has been sufficient, that is, windows which have passed such a test did not have any cracks under the influence of rapid changes in pressure when trains went past each other, despite completely different criteria (arising from other assumptions) of window assessment after getting hit by the bullet. The lack of increased bullet speed, in spite of more and more common emergence of trains whose speeds considerably exceeded $160 \mathrm{~km} / \mathrm{h}$, is likely to result from the design of train side windows. For speeds up to $160 \mathrm{~km} / \mathrm{h}$, passenger cars and multiple units were equipped with opening windows which allowed minor items to be thrown out. As for trains with a speed of at least 160 $\mathrm{km} / \mathrm{h}$, vehicles were equipped with non-opening windows, which entailed the installation of air conditioning in such vehicles.
In view of the significantly increased speed at which trains pass (speed of the train moving from the other side may be up to $350 \mathrm{~km} / \mathrm{h}$, instead of the previous $160 \mathrm{~km} / \mathrm{h}$ ), it is difficult to anticipate if the previous windscreens of the older rolling stock with a maximum speed of $120 \mathrm{~km} / \mathrm{h}$ would be properly resistant to changes in pressure. It is therefore necessary to make sure the traction vehicles (including on track machines, gang-car and others) exposed to passing high-speed trains on neighboring tracks are equipped with suitably durable windows or find out whether it is necessary to introduce other solutions which prevent vehicles of such different allowable speeds from "meeting".

\section{Conclusions}

As emphasized by authors of various publications, it is the high-speed train that influences the slower train and other objects, not the other way round. Assuming that high-speed trains are properly designed so that their structure withstands pressures and resulting forces of impact arising when running at maximum speeds, it is necessary to analyze whether other older trains which may potentially pass high-speed trains will not be exposed to excessively high pressures and resulting forces. Following the results of considerations, side windows of passenger cars, multiple units and locomotives whose windows have been tested for conformity with the UIC 566 Leaflet [7] can freely run on the same routes as high-speed trains. There is no need to replace side windows or undertake any other corrective measures. The only danger may be the entire glass being "sucked out" in the event it has been improperly mounted in the vehicle sheathing.

The analogical assumption was adopted. The assumption stated that windscreens of locomotives and multiple units in high-speed trains were properly designed so that their designs withstood pressures and resulting forces of impact arising while running at top speeds. The analysis demonstrated that a rise in the pressure on the windscreen of a high-speed train with a maximum speed of $350 \mathrm{~km} / \mathrm{h}$ which passed a slower train running at $200 \mathrm{~km} / \mathrm{h}$ would be a maximum of 1.2 times. As for lower-speed trains which go past a train running at a speed of $350 \mathrm{~km} / \mathrm{h}$, we can record a considerable increase in the pressure on the windscreen from nearly 3 times - for a train with a maximum speed of $200 \mathrm{~km} / \mathrm{h}$, through nearly 4 times - for a train with a maximum speed of $160 \mathrm{~km} / \mathrm{h}$, to over 6 times - for a train with a maximum speed of $120 \mathrm{~km} / \mathrm{h}$. Therefore, the use of various rolling stock on the same lines may entail the potential risk of damage to windscreens, particularly in older rolling stock with the maximum speed of $120 \mathrm{~km} / \mathrm{h}$. It is necessary to experimentally confirm that 
older traction vehicles likely to meet other fast trains on neighboring tracks are equipped with windows of suitable durability. If necessary, it is important that solutions preventing vehicles of such considerably different allowable speeds from "meeting" are introduced.

\section{References}

1. Assessment of potential aerodynamic effects on personnel and equipment in proximity to highspeed train operations: Safety of High-Speed Ground Transportation Systems Final Report, U.S. Department of Transportation Federal Railroad Administration, December, 1999.

2. Colin P.E.: Impulsive Pressures in the Train Passing Problem, Proceedings of the First Symposium on Road Vehicle Aerodynamics at the City University, London, 1969, Paper 11.

3. Commission Regulation (EU) No 1299/2014 of 18 November 2014 on the technical specifications for interoperability relating to the 'infrastructure' subsystem of the rail system in the European Union.

4. Gawthorpe R.G.: Aerodynamics of Trains in the Open Air, Railway Engineering International, Volume 3, Number 3, May/June, 1978.

5. Kubski K.: Badania rozkładu prędkości strumienia powietrza $w$ podmuchach wywołanych jazda pociagu i wzajemnego wpływu mijajacych się pociagów na zmiany ciśnienia statycznego działającego na ściany wagonów i na powierzchnię czołowa lokomotywy [Studies on distribution of air stream speed in slipstreams caused by a train passage and mutual impact of passing trains on changes of static pressure influencing the walls of cars and front surface of the locomotive], research work, Centralny Ośrodek Badań i Rozwoju Techniki Kolejnictwa (COBiRTK), Warszawa, January 1974.

6. PN-EN 14067-4+A1:2019-03: Railway applications - Aerodynamics - Part 4: Route aerodynamic test requirements and procedures.

7. PN-EN 15152:2019-12: Railway applications Windscreens for trains.

8. PN-EN 15273-2+A1:2017-03: Railway applications - Gauges - Part 2: Rolling stock gauge.

9. Sockel H.: The Train Passing Problem, von Karmen Institute for Fluid Dynamics, Lecture Series 48, High Speed Ground Vehicles, April 10-14, 1972, Rhode-Saint-Genese, Belgium, 1972.

10. UIC 566 Leaflet: Loadings of coach bodies and their components, $3^{\text {rd }}$ edition of 1.1.90

11. UIC 651 Leaflet: Layout of driver's cabs in locomotives, railcars, multiple-unit trains and driving trailers, $4^{\text {th }}$ edition, July 2002. 